\title{
The Social Design of Information Systems
}

\author{
Steve Sawyer ${ }^{1}$, Murali Venkatesh ${ }^{2}$, Juhani Iivari ${ }^{3}$, \\ Cathy Urquhart ${ }^{4}$, and Ben Light ${ }^{5}$ \\ ${ }^{1}$ School of Information Studies, Syracuse University, Syracuse, NY 13244-4100 U.S.A. \\ ssawyer@syr . edu \\ ${ }^{2}$ School of Information Studies, Syracuse University, Syracuse, NY 13244-4100 U.S.A. \\ mvenkate@syr.edu \\ ${ }^{3}$ Department of Information Processing, Oulu University, Linnanmaa, Oulu 90570 Finland \\ iivari@rieska.oulu.fi \\ ${ }^{4}$ Digital Business and Management Information Systems Division, Manchester Metropolitan \\ University Business School, Mancheste M1 3GH, U.K. \\ c.urquhart@mmu.ac.uk \\ ${ }^{5}$ School of Media, Music and Performance, University of Salford, Salford M3 6EN U.K. \\ B. Lighteslaford.ac.uk
}

\section{Introduction}

This panel focuses on issues of designing information systems to both account for, and better support, the increasingly social functions that computer-based technologies play. The goal of this panel is to serve as a forum to advance and discuss initial principles for what we are calling the social design of information systems. By social design we mean to emphasize that the presence and uses of information systems play an often significant role in supporting the reshaping social relations, social structures, social boundaries, and social norms. Many such aspects of this reshaping are highlighted in the scholarship of IFIP 8.2 members, and with this panel we seek to focus the collective attention of the assembled scholars to shift attention from "problematizing" the issues with designing information systems toward advancing socially relevant design principles (e.g., Iivari et al. 1998).

Issues with information systems design and development have always been a core concern of the IFIP 8.2 community. Since the 1970s, much of the IFIP 8.2 scholarship has focused on illuminating issues and the assumption of organizationally oriented information systems design-often with a critical stance (e.g., Hedberg 1975). This critical stance is certainly embodied in the rich tradition of critical theoretic research. However, the critical stance found in much IFIP 8.2 scholarship means, more broadly, questioning assumptions-conceptually and empirically-and challenging orthodox or taken-for-granted stances (e.g., Boland 1987).

We observe, like many, that contemporary information systems are increasingly expected to span organizational boundaries and the design of information systems is no longer a functional focus or even a unilateral organizational issue (Benkler and Nissenbaum 2006). The interorganizational focus of contemporary information systems calls into question some of the taken-for-granted design principles and practices of more organizationally focused approaches such as the importance of a production-oriented purpose, the need for top management support, or even the 
explicit involvement of organizational actors in the system design, development, and deployment. Departures (with both positive and negative effects) are commonly identified in the literature regarding large-scale interorganizational information systems such as interconnected national identity card and passport systems, digital health-care records, and cooperative information-sharing and e-commerce systems such as Amazon.com. Concurrent with the shift toward interorganizational systems is the rise of Internet-based social media applications that involve more socially oriented functionality. Certainly contemporary web-based social media platforms/applications like Twitter, Flickr, and Facebook are contemporary examples of such systems.

This trend toward explicitly social functionality is seemingly profound: organization leaders are increasingly more aware that social functionality must be embedded in information systems-and organizational workers are coming to expect this to be the norm. Organizational leaders are, however, struggling with how best to accommodate socially relevant (and often divisive) requirements. For example, what are the proper ways to model social behavior? Given that these information systems are designed to always span organizational boundaries (becoming interorganizational systems and demanding new collaborative forms of governance), what sorts of crossboundary social interactions are to be supported (or made more difficult)? Certainly the design needs for such socially complex systems are likely to differ from the set of what we are labeling organizational design principles, which are focused on a particular functional or cross-functional aspect of an organization.

Given these trends, what are the basics of social design (versus organizational design) of an information system? For this panel, we consider two aspects of this issue.

1. How do designers grapple with the tensions of developing for role-based organizational uses and users versus . the more socially complex users of social software?

2. How do designers grapple with the issues of social needs for users in their work?

\section{Panelists}

To do this, we bring together four scholars who have, through their work, focused on various aspects of social design (with Sawyer serving as moderator).

Juhani Iivari will focus on aspects of social design and social use by drawing from three streams of his research: (1) philosophical bases of information systems development approaches, (2) comparative analyses of information systems development methodologies (e.g., Iivari et al. 1998), and (3) some recent empirical material on individual's uses of Facebook.

Ben Light will draw upon two ethnographic projects of online communities to illuminate social design issues. Study one is based on an Internet dating site (Light 2007; Light et al. 2008). Study two concerns digital gaming experiences on and beyond the screen (Fletcher and Light 2008). By considering sets of socio-technical arrangements that, as yet, have not been subject to much scrutiny within information systems, these ethnographies help frame what social design will need to consider.

Cathy Urquhart will build on her work in the areas of information and communication technologies (ICTs) and social inclusion. ICTs are increasingly seen as a means for social inclusion (e.g., Urquhart et al. 2008). She will discuss how, in a 
world where we assume that everyone is accessing the Internet in the same way, one design of a web site may not fit all communities and can exclude people as well as include them. These issues of design can cover language (Diaz Andrade and Urquhart 2009) and cultural and visual aspects (Ornelas and Gregory 2009; Tan et al. 2006). She will also discuss how the design of some mainstream websites such as Facebook might shape social interactions and make assumptions about their users, who are in fact extremely varied.

Murali Venkatesh will build from his ongoing work in community networks research (Venkatesh 2003) and influences of Simon (1996). While many in information systems point to Simon's guidance on design science, few note that he spends an equal amount of time discussing social design.

\section{Panel Structure}

The panel is structured in four distinct phases. Two of the phases rely on participation with the audience. Principles guiding this design are to

1. Draw on the panelist's expertise and experience to provide initial principles and issues with social design

2. Fully engage participants in advancing these principles and surfacing issues

For the first phase, panelists will provide one or more tentative social design principles and one or more social design issues. This set of tentative principles and issues will serve as the basis for discussions in the second phase. The first phase will take 20 minutes (including introductions).

The second phase of the panel time will be done in concert with the audience and last for about 30 minutes. The members of the panel audience will work together (or alone; it will be their choice) to respond to the initial positions outlined by the panelists. These responses can come in one of three forms: (1) extension- modifying or extending a current principle with additional insight, specificity, or direction, (2) challenge-providing argumentation or guidance which challenges or seeks to refute the initial position, and (2) addition-providing additional principles or issues that were not provided initially. To enact this phase, panelists and the moderator will help to organize groups and provide support. The ad hoc groups formed among audience members will be given a set of colored note cards (green for extension, red for challenge, and orange for addition). These note cards will be collected at the end of the second phase.

The third phase will last 10 minutes and will have two parallel activities. The panelists will use this time to reflect on what they have learned by working with various audience groups. In parallel to this, the moderator will organize the responses to provide some initial feedback from what the audience generated and to highlight provocative or insightful feedback for further discussion in the final phase.

In the fourth phase, the panelists and audience will participate in a more open discussion of the selected feedback generated in phase two and summarized in phase three. In this phase, the goal is to begin identifying common positions and to identify areas of distinct differences regarding social design principles and issues. 
Following the panel, a full summary of the discussion, responses, and points will be posted to LOCATION so that participants can have access to the material they helped to cocreate.

\section{References}

Benkler, Y., Nissenbaum, H.: Commons-Based Peer Production and Virtue. The Journal of Political Philosophy 14(4), 394-419 (2006)

Boland, R.J.: The In-formation of Information Systems. In: Boland, R.J., Hirschheim, R.A. (eds.) Critical Issues in IS Research. John Wiley, New York (1987)

Diaz Andrade, A., Urquhart, C.: ICTs as a Tool for Cultural Dominance: Prospects for a TwoWay Street. Electronic Journal of Information Systems in Developing Countries 15(2), 108-132 (2009)

Fletcher, G., Light, B.: Making the Game Work? Lessons from Ethnographies of SingStar. In: CITASA Workshop, American Sociological Association, Boston (2008)

Hedberg, B.: Computer Systems to Support Industrial Democracy. In: Mumford, E., Sackman, H. (eds.) Human Choice and Computers. North Holland, New York (1975)

Lamb, R., Kling, R.: Reconceptualizing Users as Social Actors in Information Systems Research. MIS Quarterly 27(2), 197-235 (2003)

Light, B.: Introducing Masculinity Studies to Information Systems Research: The Case of Gaydar. European Journal of Information Systems 16(5), 658-665 (2007)

Light, B., Fletcher, G., Adam, A.: Gay Men, Gaydar and the Commodification of Difference. Information Technology and People 21(3), 300-314 (2008)

Iivari, J., Hirschheim, R., Klein, H.K.: A Paradigmatic Analysis Contrasting IS Development Approaches and Methodologies. Information Systems Research 9(2), 164-193 (1998)

Ornelas, Y., Gregory, J.: Design for Social Inclusion and Social Sustainability. Special Session Organizers. In: Proceedings of IASDR 2009: Design Rigor \& Relevance, Seoul, Korea, October 18-22 (2009)

Simon, H.A.: The Sciences of the Artificial, 3rd edn. MIT Press, Cambridge (1996)

Tan, F.B., Lin, H.J., Urquhart, C.: An Exploratory Study of the Design Preferences of U.S. and Chinese Virtual Communities. International Journal of E-Business Research 2(3), 47-69 (2006)

Urquhart, C., Liyanage, S., Kah, M.: ICTs and Poverty Reduction: A Social Capital and Knowledge Perspective. Journal of Information Technology 23(3), 203-213 (2008)

Venkatesh, M.: Public Participation in Broadband Network Development. In: Day, P., Schuler, D. (eds.) Community Networks and the Public Sphere. Routledge, London (2003) 